\title{
Topological Optimization of a Supporting Part of a 3D Printer Pad
}

Martin Pollak, Jakub Kascak, Monika Torokova, Marek Kocisko, Jozef Dobransky

Faculty of Manufacturing Technologies with a seat in Presov, Technical University of Kosice. Bayerova 1, 08001 Presov. Slovak Republic. E-mail: martin.pollak@tuke.sk

Generative design is one of the most promising means of new product development in the world. It allows formation of organic structures that brings various benefits, e.g. in the form of savings of material and production costs. Generative design includes several types of technology, topological optimization included. The paper addresses the technology of topological optimization implemented on the support part of the 3D printing pad. The result of optimization is the creation of a new, more suitable design concept through the Altair Inspire optimization software.

Keywords: Generative design, Topological optimization, Additive technology, FFF/FDM technology, Altair Inspire software

\section{Introduction}

Generative design is a term encompassing multiple types of technology involved in this progressive kind of product modelling. These technologies include topological optimization, biomimicry, experimental design method and lattice structure generation. Biomimicry mimics patterns or processes from nature that are subsequently applied in industry. In case of the lattice structure generation, it is a targeted and planned weakening of the model's structure by placing different kinds of crystalline lattices, which are the result of a prior analysis. The experimental design method or experimental design is a discipline of mathematical statistics, which deals with data collection in various situations where the information obtained is biased by randomness. Such experiments may also include the intervention of the experimenter, the aim of which is to establish the effect of the intervention. Topological optimization involves creating models based on changes in the model's primary state under load. The resulting shape is generated on the basis of the loads acting on the draft model, which is reduced or weakened by the removal of unnecessary material from the sites of zero or minimal load. [1], [2]

Due to manufacturing oriented topological optimization which was studied in last two decades, the design created as a result of this process was in strictly friendly to manufacture and close to optimal state. Recently with the onset of additive manufacturing these rules and restriction were changed. The geometrical restrictions and complexity of optimized model were greatly reduced, due to the layer by layer method of production (Liu et al. 2018) [3]. Identification of numerous of variations of the practical difficulties based on conversion of the mathematical results of topological optimalization into a usable CAD model for additive manufacturing are well described in publication (Brackett et al. 2011) [4]. As they mentioned, the high degree of complexity of optimization results for additive manufacturing causes that any manual conversion to CAD model is strictly unreasonable. In present are these difficulties reduced thanks to partially automatic process adapted to additive manufacturing and its constrains. These constrains pertain to post processing (Langelaar et al. 2017) [5], minimum size of features (Zhou et al. 2015) [6], and effective use of supporting structures (Mirzendehdel et al. 2016) [7].

The paper addresses the topological optimization processed in the Altair Inspire software on the model of the support part of a 3D printing pad. The aim of the optimization process is to eliminate undesirable effects on the model created by the FFF technology. Problems arising from and affecting the printing process itself can be divided into several groups. These groups are, for example, errors caused by a misconfiguration of the software that controls each print parameter, such as a printer pad temperature, nozzle temperature, printing speed and others. The second category is human error, which may include poor storage of printing material, failure to maintain equipment, or lack of qualification. As 3D printing technology is becoming increasingly widespread, new types or copies of commercial equipment are emerging, the execution of which is not always satisfactory and structurally correct. This results in another group of failures, consisting of errors resulting from the design of the device itself, which include various types of unwanted vibrations, poor geometry of the structure or other mechanical or electrical deficiencies. [8-10] 


\section{Characteristics of the FFF equipment, se- lection and justification of optimization elements}

An example of a similar device and the device used for topological optimization in direct connection with the FFF technology is the commercially available 3D printer TEVO Tarantula (Fig. 1). It is a printer of a simple, cartesian-type design, i.e. working in direction of the $x, y, z$ axes. TEVO is one of the more affordable FFF devices, but its availability comes at the expense of a large number of bugs and shortcomings that are ideal for validating our theory. The design of this device has many components suitable for optimization, but in this case we decided to optimize the base of the printing pad. The original pad is mounted on $V$-shaped rubber wheels that move directly along the structure. This way of moving the axes in the FFF devices is quite frequent, but in this case the travel is located on an

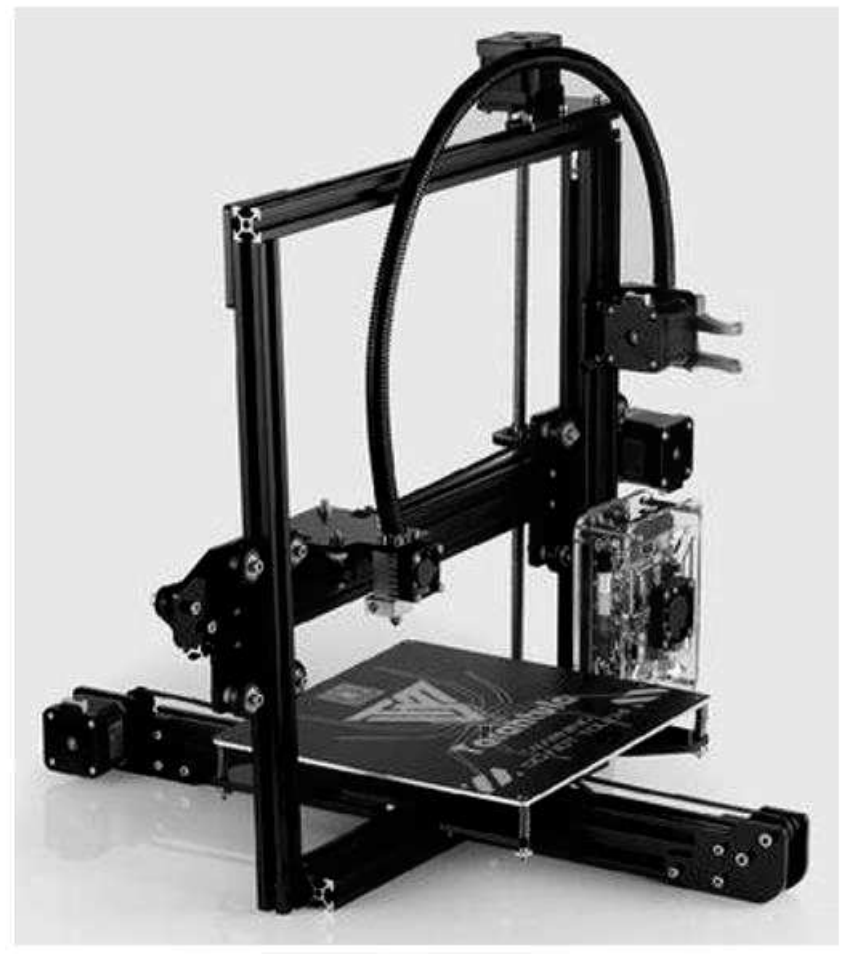

Fig. 1 Commercially available TEV

2.1 The approach of addressing the insufficient print pad features

Based on the prior identification of the printing pad problems, it would probably be appropriate to replace the component with an aluminium one, the mechanical properties of which would solve all the drawbacks. Given the idea of the original RepRap project, which started in 2005, in the era of available devices capable of producing and reproducing their own components, it is easier and less costly to create a new acrylic base. This is then directly attached to the heated printing pad by means of screws and springs. [11]

Therefore, the problems emerging in the printing process are the following:

- insufficient mechanical properties of the acrylic pad due to its dimensions,

- deformation of the pad due to pressure of springs used for manual adjustment of the print base height,

- heat transferred from the printing pad to the acrylic material by means of metal screws and springs,

- vibration resulting from machine movements, model's weight increase during the printing process, and insufficient base rigidity.

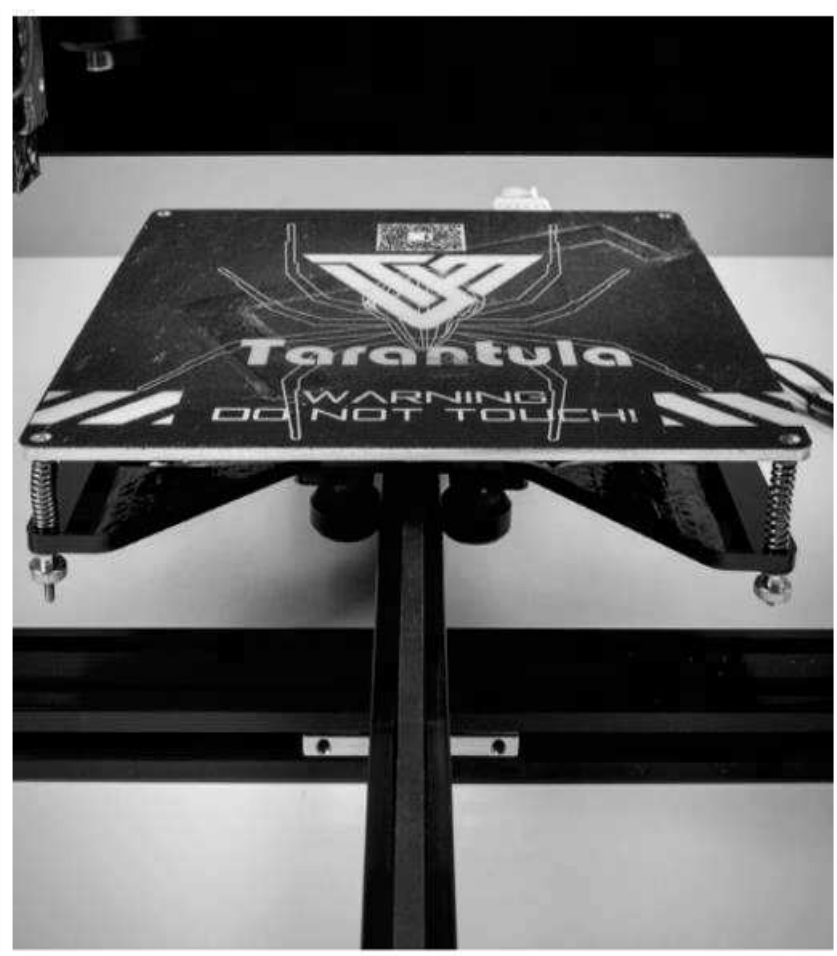

Tarantula device selected for optimization

component using optimization software. For this purpose, a base structure consisting of five components was selected. However, before the optimization process itself, this assembly had to be modified.

Topological optimization is a calculation method used in designing digital models. It serves the purpose of designing the most suitable geometric shape of a body or an assembly. In this way we can design the shape of the product with considerable savings in terms of the volume of material and, therefore, weight, while maintaining its strength requirements. 

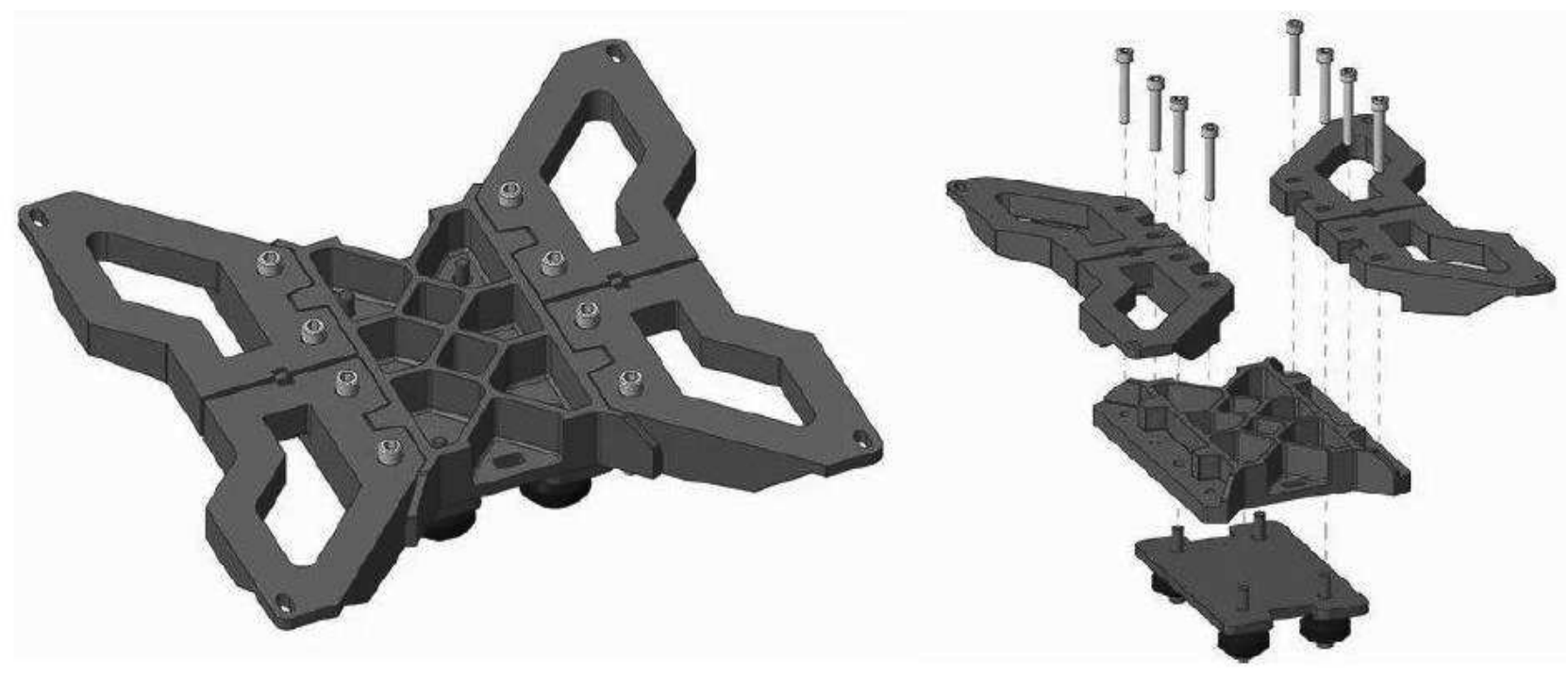

Fig. 2 Print pad base model draft design

It is important to know the so-called "Boundary conditions":

- taking away the necessary degrees of freedom in space,

- magnitude and direction of forces and moments,

- assignment of material properties.

After analysing and defining the boundary conditions, it is important to establish the calculation method or the goals of this optimization. The result of the calculation is, therefore, the ideal shape of the body, assembly or structure (resembling a cellular structure, also called a bionic structure), which, at the same time, meets the mechanical and strength requirements and is simultaneously as light-weight as possible (with a certain safety factor).

Products that are thus "optimally lightened" typically have a hollow and metallic shape that is difficult to manufacture by conventional manufacturing methods, or economically inefficient, as can be seen in Fig. 3. Therefore, in many cases, additive manufacturing technology is a suitable method of manufacturing topologically optimized parts. [12], [13]

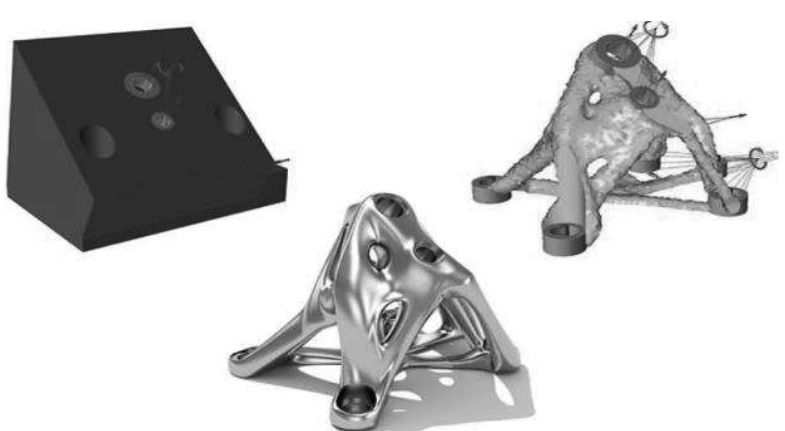

Fig. 3 Examples of model shape optimization [14]

The selected adjustments must be made with respect to the FFF technology that will create the subsequent components. As can be seen in Fig. 4 and Fig. 5 , the shape of the model used for optimization has a large effect on the propagation of the simulated loads. For this particular example, a load was applied as a result of spring pressure on the pad. This is directly related to the resulting shape of the optimized element. The shape in Fig. 4 shows the "bypassing" of the load around the recess intended to relieve the model. In addition, a model of this nature would require the use of an extreme amount of support material or would be more suitable for another type of additive technology, e.g. DLP, SLA, SLS.
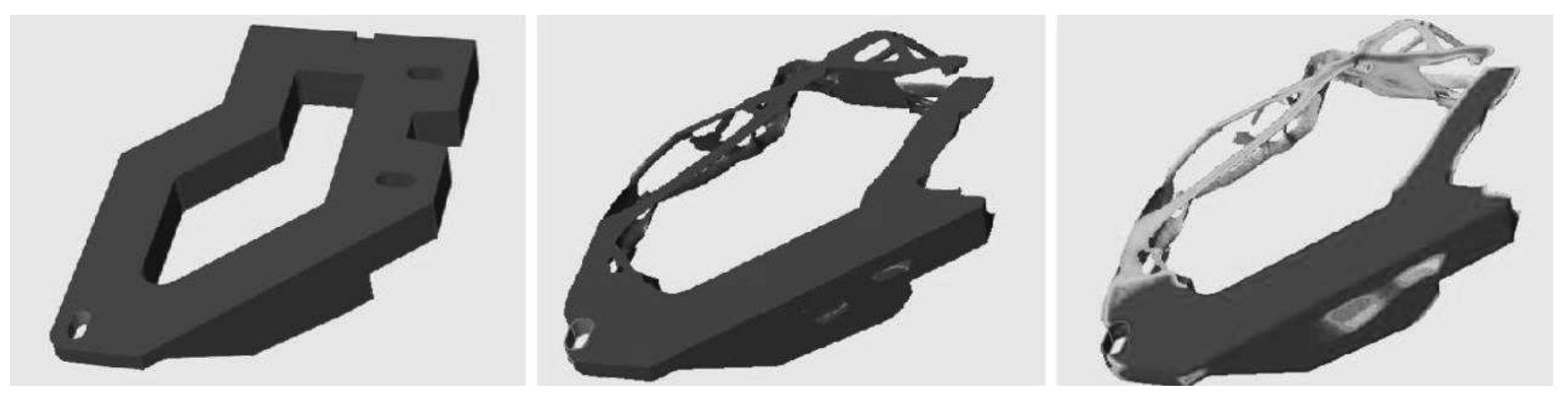

Fig. 4 Demonstration of the optimization process with relieving the model of its weight 
The model of Fig. 5 is more straightforward in terms of stress propagation. As already mentioned, the ideal model for this purpose would be a model without any unnecessary geometric and shape elements. The final adjustment consists of the selection of material from the implemented library and the definition of values determined by boundary conditions and the establishment of fixed points needed for the optimization to run its course.
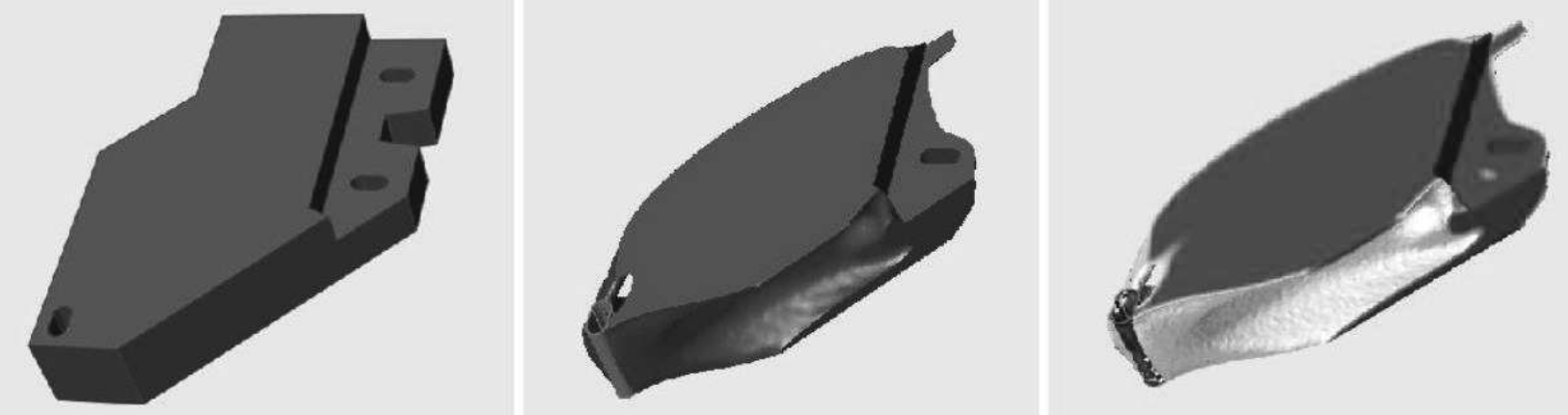

Fig. 5 Optimizing the model without relieving it of its weight

\subsection{Analysis of boundary conditions}

Based on the relationships for calculating the maximum weight of the PLA plastic material, which is the one most commonly used in this type of equipment, and Tab. 1 containing the necessary material data, we can derive the model's maximum weight. This results from the maximum printing volume the device is able to produce and the density of the laminated PLA plastic. In this way we can determine the maximum load, or the force exerted on the printing pad at its support points, i.e., the screw connections, which are in direct contact with the printing base pad. [15], [16]

Tab. 1 Mechanical properties of original material and of its substitute

\begin{tabular}{|c|c|c|c|c|c|}
\hline $\begin{array}{c}\text { Ma- } \\
\text { terial }\end{array}$ & $\begin{array}{c}\text { Young's Modulus of Tensile } \\
\text { Elasticity [MPa] }\end{array}$ & $\begin{array}{c}\text { Shrink- } \\
\text { age [\%] }\end{array}$ & $\begin{array}{c}\text { Density } \\
{[\mathbf{k g} / \mathbf{m} 3]}\end{array}$ & $\begin{array}{c}\text { Flexural } \\
\text { Strength [MPa] }\end{array}$ & $\begin{array}{c}\text { Heat Resistance of } \\
\left.\text { Products [ }{ }^{\circ} \mathbf{C}\right]\end{array}$ \\
\hline $\begin{array}{c}\text { PMM } \\
\text { A }\end{array}$ & 2930 & $0.2-0.8$ & 1195 & 72.39 & $105 \pm 20$ \\
\hline ABS & 2971 & $0.3-0.7$ & 1045 & 82.73 & 105 \\
\hline
\end{tabular}

The resulting boundary condition is the deformation brought about by tightening of the screws, that also serve as a means for calibrating and adjusting the zero position of the printing pad. As already mentioned, the technical condition of these devices is not always good, thus tightening the screws or the spring force will not be the same in all parts of the base. For this reason, when optimizing, we assume maximum tightening of the screws, i.e. similar to the printing volume, with the maximum possible deflection of the base caused by the springs. These values can be derived from a simple relationship resulting from the stiffness of the springs used and the difference in length of the springs before and after tightening the screws. The last of the boundary conditions used in this optimization is the printing pad temperature. The software used does not have a function that could generate the shape of the model based solely on temperature, but it can take into account the temperature acting on a particular material. This means that during the model generation in terms of the spring load and its weight acting upon it, the optimization takes into account the material properties based on the specific temperature acting on the optimized models.

\subsection{Model preparation}

The preparation of the model consists of several steps. The first step is to select the components or component parts subject to optimization. In our case, these components are the individual "wings" of the printing base pad. The body itself, to which the "wings" are attached, namely onto the travel in the yaxis direction, is considered to be static in the optimization calculation. The base body is connected to the optimized parts through eight screws, as can be seen in Fig. 2. The next step involves creating the socalled optimized components partitions. These are created to maintain the exact positions of the holes that would otherwise be part of the optimized volume. This would result in poor or no possibility of anchoring the connecting bodies. For this reason, partitions are made on optimized models as shown in Fig. 3. The next step is to create an ideal part to optimize, in general, simplified models are used for this purpose without recesses, shrinks, relief holes, etc. In our case, the original model has recesses to save material during printing. However, these are not entirely satisfactory for optimization, which can also be seen 
in the following examples. Fig. 5 shows that the least complicated and shortest route to bottlenecks in this case is the shortest route that can be selected. In the case of a recess-free model, an $8 \%$ overall ABS material savings in printing a component has been demonstrated. These savings are largely due to the absence of organic parts of the model, which in case of the FFF technology require a larger amount of support material. [17], [18]

\section{Optimization process implementation}

Based on the results of the analysis shown in Fig. 6 and Fig. 7, the software automatically suggests possible areas with different percentages of material savings. Red areas are with $100 \%$ of element density, white areas $50-70 \%$ and blue areas with $5 \%$ or less as can be seen despite the same boundary conditions, these results are significantly different. Due to several different parameters by which we can intervene in the optimization process itself, we are related with our solution focused on three specific. Among the parameters that can be manually moved into the optimization process are e.g. maximum and minimum width of walls, frequency of oscillation of the system, the way to draw the geometry of the optimized part, all of those parameters are calculated based on element density of appropriate section. For our solution mainly three of these parameters are authoritative. Since we consider components that are created using FDM technology. Of course the device to work with certain clearances that are characteristic for common
FFF/FDM devices. Due to this fact is optimization based on frequencies, oscillations is ineffective, so default value was used. Due to parameter limiting the minimum width of walls or columns set to $120 \%$ of the value of the hole diameter located on the print nozzle. It's for a reason of the mechanical limitation of the printhead for which it is not physically possible to make the element narrower such as the diameter of the nozzle. The method of plotting the geometry of the optimized areas was chosen so that each of the models had one flat contiguous surface. This will provide us with a better placement of the model on printing pad and increase the adhesion of the whole model. The last parameter was the safety factor, which we left at 1.2 due to the recommendations of the resources available for the software.

For the sake of the paper's clarity, only partial illustrations of the optimization process were chosen for demonstration. However, the process ran in a real scale and used the entire the printing base pad assembly. Illustrations of Fig. 6 and Fig. 7 show the course of the optimization process under a particular type of load. In both of these processes, the temperature of the printing pad, set to the maximum value used for printing PLA plastics, which corresponds to $70{ }^{\circ} \mathrm{C}$, is taken into account [19]. Fig. 6 shows the course of the loads from the screws connecting the base body with the optimized part all the way to the part connecting the wing to the plate itself. Fig. 7 shows the course of the load caused by the weight of the printed object. At first glance it is obvious that these are loads with a similar deformation effect.
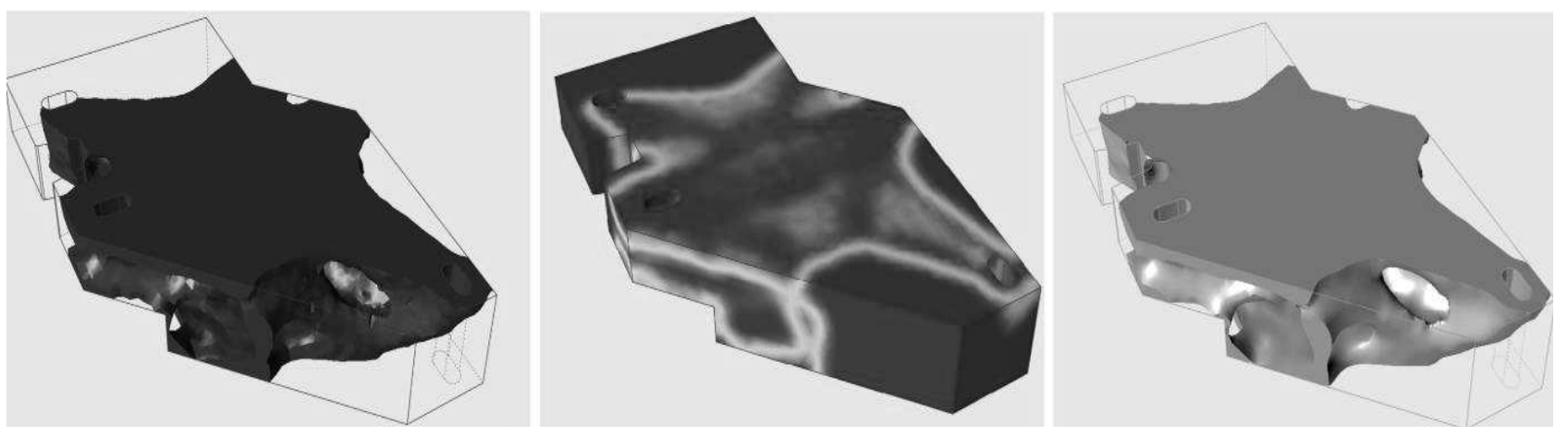

Fig. 6 Optimization process for spring load
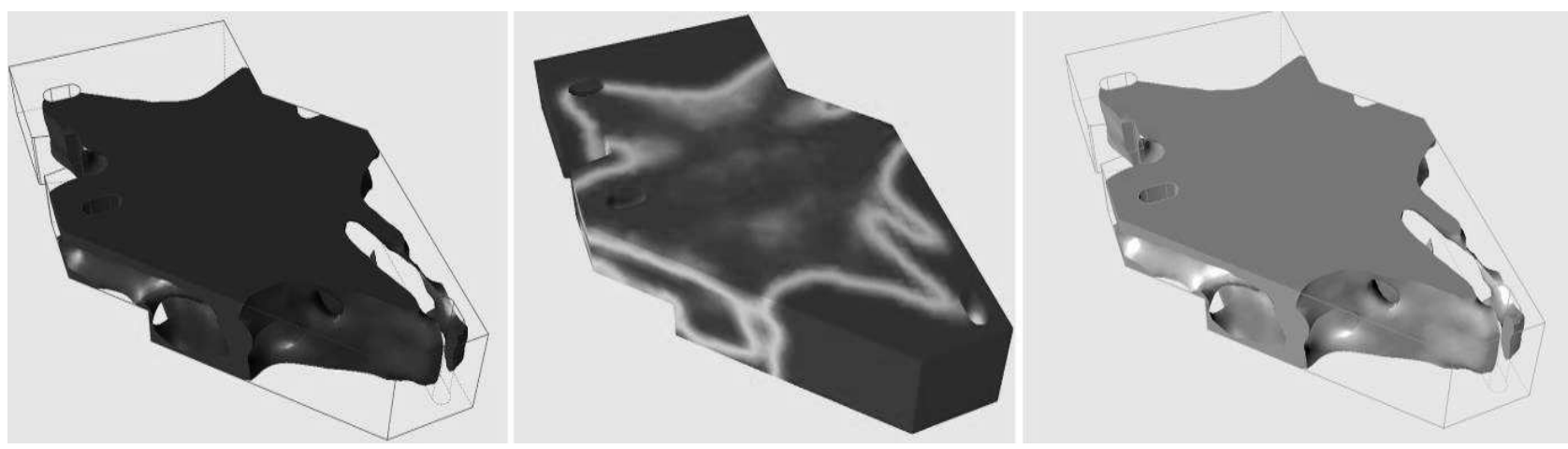

Fig. 7 Course of loads caused by the weight of the printed object 
Optimization results show three types of results. The first is the optimized area that is delimited by the loads. This area shows that the material is only found in areas where it is needed in terms of loads. The second result is a demonstration of stress propagation across the model volume, with specific values in each area. Finally, the final model, the so-called polyNURBS model, is displayed. This model can be modified, customized and exported in the selected format within the program interface. In case of a modification, however, a new data validation is necessary, i.e. a new shape optimization starts again. [20]

As already mentioned, Fig. 6 and Fig. 7 are optimized for particular load types. However, the purpose of this paper is to optimize the entire print pad with all of its elements. As can be seen in Fig. 8, the entire model is shown with all the loads; i.e. that from the temperature, deflection and weight. This model is then optimized. During optimization, all these loads are taken into account and the resulting shape corresponds to the parameters entered, and the results are recorded in Tab. 2.

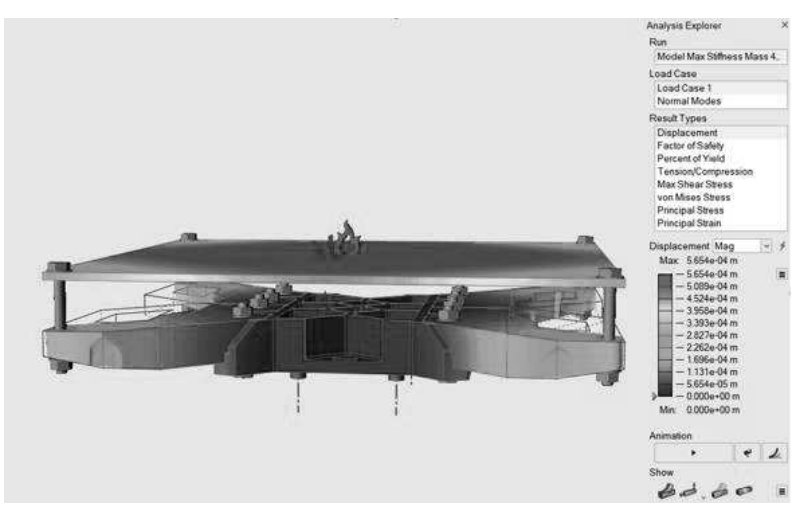

Fig. $\boldsymbol{8}$ Print base pad optimization results

Tab. 2 Optimized model analysis results

\begin{tabular}{|c|c|c|c|c|c|c|c|}
\hline & $\begin{array}{c}\text { Max. Dis- } \\
\text { placement } \\
{[\mathrm{m}]}\end{array}$ & $\begin{array}{c}\text { Min. Factor } \\
\text { of Safety }\end{array}$ & $\begin{array}{c}\text { Percent of } \\
\text { Yield [\%] }\end{array}$ & $\begin{array}{c}\text { Tension } \\
{[\mathbf{P a}]}\end{array}$ & $\begin{array}{c}\text { Max. Shear } \\
\text { Stress } \\
{[\text { Pa] }}\end{array}$ & $\begin{array}{c}\text { Max. von } \\
\text { Misses } \\
\text { Stress [Pa] }\end{array}$ & $\begin{array}{c}\text { Principal } \\
\text { Stress } \\
{[\text { Pa] }}\end{array}$ \\
\hline $\begin{array}{c}\text { Optimized } \\
\text { model }\end{array}$ & $5.564 \mathrm{e}^{-4}$ & 5.9 & 17 & $6.811 \mathrm{e}^{6}$ & $4.127 \mathrm{e}^{6}$ & $7.650 \mathrm{e}^{6}$ & $7.096 \mathrm{e}^{6}$ \\
\hline
\end{tabular}

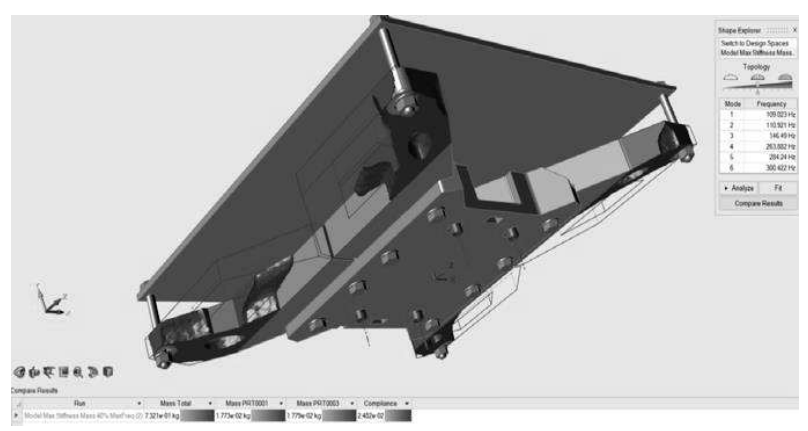

Fig. 9 Final model of the optimized print base pad
The resulting model is shown in Fig. 9, which represents the optimization process result. Thus, the optimization process results in a new component satisfying predetermined boundary conditions.

The advantages of the optimized model are lower weight, less material consumption and production time. Another fact is that this model is adapted to a specific type of technology. The production of the component is thus possible by means of an existing, optimized device.

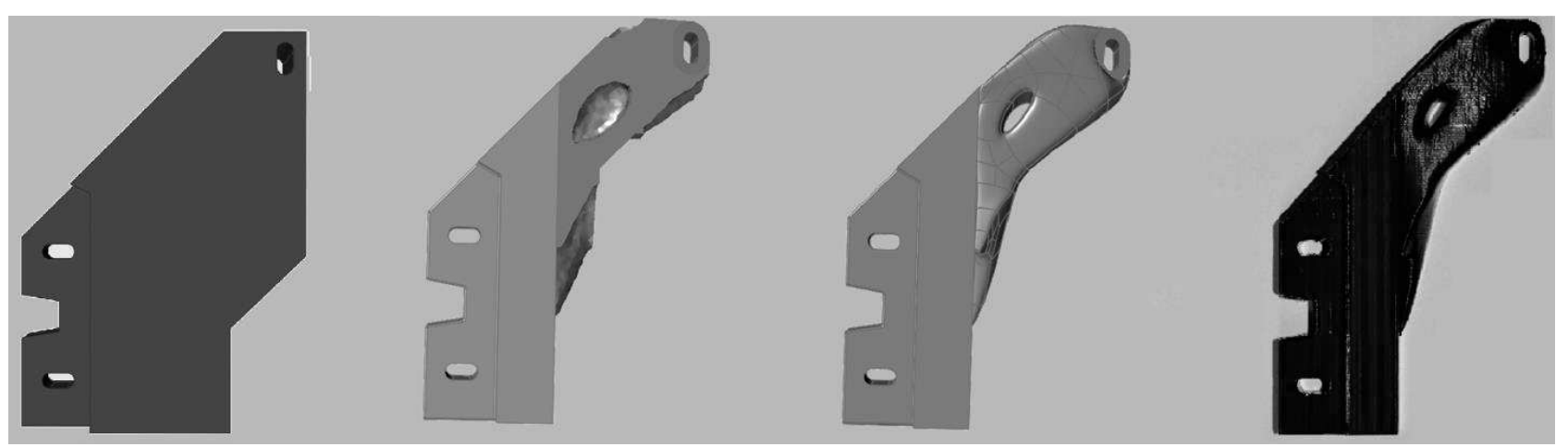

Fig. 10 Optimization process chronology

\section{Conclusion}

As the technological process of additive manufacturing and the reduction of the prices of material progresses further, also thanks to the method of topological optimization of the parts proposed, the topo- logical optimization trend is expected to grow gradually in all areas of industry in the coming years [21]. Topological optimization is a method for designing the most suitable geometric shape of a body or an assembly under known boundary conditions. When using it in practice, we can design a product's shape 
with considerable savings in terms of its volume and, therefore, weight. Products that are "optimally lightened" in this way usually have a shape that is difficult to produce by conventional methods of manufacture, or such production is economically inefficient. Therefore, in many cases, it is exactly the additive manufacturing that is a suitable method of production. The paper describes the possibility of using a software solution as a tool for topological optimization and its applications for additive manufacturing technology. It describes and thoroughly informs on the model preparation; establishment of boundary conditions and it presents concrete case of a component optimization. On the example of a printing base pad used in a 3D printer, it thoroughly describes a process of the pad preparation, optimization and the results themselves, which show the possibility to adapt the shape of the optimized parts to suit a particular type of production. Further, it describes the validation of the analysed data and the final evaluation, which shows advantages of the optimized components. The result of the calculation is, therefore, an ideal body shape, which simultaneously meets the mechanical and strength requirements and, at the same time, is as light-weight as possible. One of the other goals for validating the analysed data is to place optimized ABS components on the FFF equipment base and to verify the correctness of the analysis through benchmark tests and laboratory measurements.

\section{Acknowledgement}

This article was created thanks to the framework of the project VEGA no. 1/0026/19 and project $A P V V-16-0355$.

\section{References}

[1] PANDA, A., DYADYURA, K., VALICEK, J., HARNICAROVA, M., ZAJAC, J., MODRAK, V., PANDOVA, I., VRABEL, P., NOVAKOVA-MARCINCINOVA, E., PAVELEK, Z. (2017). Manufacturing technology of composite materials-principles of modification of polymer composite materials technology based on polytetrafluoroethylene. In: Materials, Vol. 10, No. 4, pp. 1-20. ISSN 19961944.

[2] TKAC, J., POLLAK, M. (2019). Behavior of the beam with a lightweight porous structure in its core. In: Advances in Manufacturing Engineering and Materials, pp. 502-510. ISBN 978-3-31999352-2.

[3] LIU, J., GAYNOR, A. T., CHEN, S., KANG, Z., SURESH, K., TAKEZAWA, A., LI, L., KATO, J., TANG, J., WANG, CH. C. L, CHENG, L., LIANG, X., TO, A. C. (2018).
Current and future trends in topology optimization for additive manufacturing. In: Structural and Multidisciplinary Optimization, Vol. 57, No. 6, (2018), pp. 2457-2483.

[4] BRACKETT, D., ASHCROFT, I., HAGUE, R. J. M. (2011). Topology optimization for additive manufacturing. In: 22nd Annual International Solid Freeform Fabrication Symposium - An Additive Manufacturing Conference, pp. 348-362.

[5] LANGELAAR, M. (2019). Integrated component-support topology optimization for additive manufacturing with post-machining. In: Rapid Prototyping Journal, Vol. 25, No. 2, pp. 255265. ISSN 1355-2546.

[6] ZHOU, M., LAZAROV, B. S., WANG, F., SIGMUND, O. (2015). Minimum length scale in topology optimization by geometric constraints. In: Computer Methods in Applied Mechanics and Engineering, Vol. 293, pp. 266-282.

[7] MIRZENDEHDEL, A. M., SURESH, K. (2016). Support structure constrained topology optimization for additive manufacturing. In: Computer-Aided Design, Vol. 81, pp. 1-13.

[8] DVORAK, K., ZARYBNICKA, L., DVORAKOVA, J. (2019). Quality parameters of 3D print products by the DMLS method. In: Manufacturing technology, Vol. 19, No. 2, pp. 209215. ISSN 1213-2489.

[9] KELLNER, T., KYNCL, J., PITRMUC, Z., BERANEK, L., KANAK, M., KYNCL M. (2019). Production process planning in additive manufacturing and conventional machining technology manufacturing system. In: Manufacturing technology, Vol. 19, No. 2, pp. 232-237. ISSN 1213-2489.

[10] DANA, M., ZETKOVA, I., MACH, J. (2018). Mechanical properties of Inconel Alloy 718 produced by $3 \mathrm{D}$ printing using DMLS. In: $\mathrm{Ma}$ nufacturing Technology, Vol. 18, No. 4, pp. 559562. ISSN 1213-2489.

[11] NOMURA, T., DEDE, E. M., LEE, J., YAMASAKI, S., MATSUMORI, T., KAWAMOTO, A., KIKUCHI, N. (2015). General topology optimization method with continuous and discrete orientation design using isoparametric projection. In: International Journal for Numerical Methods in Engineering, Vol. 101, No. 8, pp. 571-605.

[12] MONKOVA, K., MONKA, P. P., TKAC, J., TOROK, J., SUBA, O., ZALDEK, M. (2019). Research of Young's modulus of the simple lattice structures made from plastics. In: Mechanical and Aerospace Engineering: proceedings of the 2019 
IEEE 10th International Conference, pp. 555-558. ISBN 978-1-7281-5534-0.

[13] SASALA, M., HRIVNIAK, L., ONDOCKO, S., SVETLIK, J. (2020). Výskum úpravy kruhových rozmerov v CAD programoch používaných pre tlač na 3D tlačiarni. In: Novus Scientia 2020, Slovakia, pp. 225-228. ISBN 978-80-5533500-1.

[14] [09. 03. 2020], Altair Inspire. Available on the internet: http://www.advanced-eng.cz/brochure/Inspire_0002_brochure_US_0818WEB.pdf

[15] STEJSKAL, T., DOVICA, M., SVETLIK, J., DEMEC, P. (2019). Experimental assessment of the static stiffness of machine parts and structures by changing the magnitude of the hysteresis as a function of loading. In: Open Engineering, De Gruyter, Vol. 9, No. 1, pp. 655-659. ISSN 2391-5439.

[16] [09. 03. 2020], 3D printing technology choice: FDM v/s SLA v/s SLS. Available on the internet: https://manufactur3dmag.com/3d-printing-technology-choice-fdm-v-s-sla-v-s-sls /
[17] SETOODEH, S., ABDALLA, M. M., GURDAL, Z. (2005). Combined topology and fiber path design of composite layers using cellular automata. In: Structural and Multidisciplinary Optimization, Vol. 30, No. 6, pp. 413-421.

[18] ANSOLA, R., CANALES, J., TARRAGO, J. A., RASMUSSEN, J. (2002). On simultaneous shape and material layout optimization of shell structures. In: Structural and multidisciplinary optimization, Vol. 24, No. 3, 2002, pp. 175-184.

[19] LANGELAAR, M. (2016). Topology optimization of 3D self-supporting structures for additive manufacturing. In: Additive manufacturing, Vol. 12, Part A, pp. 60-70.

[20] FORSTER, A. M. (2015). Materials testing standards for additive manufacturing of polymer materials: State of the art and standards applicability. In: Materials Science, pp. 67-123.

[21] POOR, P., BASL, J. (2019). Readiness of companies in relation to Industry 4.0 implementation. In: 17th International Scientific Conference on Hradec Economic Days, Czech Republic. 